\title{
Surgical treatment of cardiac tumours an overview and presentation of interesting cases
}

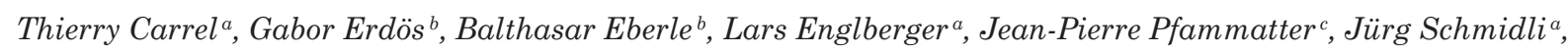
Alexander Kadner, Mario Stalder ${ }^{a}$

a Clinic for Cardiovascular Surgery, University Hospital Berne, Switzerland

b Institute of Anaesthesiology, University Hospital Berne, Switzerland

c Division of Paediatric Cardiology, University Hospital Berne, Switzerland

\section{Summary}

Primary neoplasms of the heart are relatively rare. Their incidence varies between $0.001 \%$ to $0.3 \%$ of individuals in autopsy series. Even the most common primary tumour - cardiac myxoma - is estimated to occur in fewer than two or three people per 100000 population. When primary cardiac tumours occur consequences may be considerable because of the crucial nature of the various structures involved. The complications attributed to such tumours depend on their location, size, mobility, friability, and the invasiveness of tumour growth. Primary tumours of the heart and pericardium are more important for their local effects than for their potential metastatic behaviour. They usually present as rhythm disturbances, contractility abnormality, obstruction, valvular regurgitation, embolic event, or pericardial effusion. In some instances, presentation may mimic myocardial ischaemia, valvular disease, cardiomyopathy, or local infectious disease.

Numerous imaging modalities (transthoracic and transoesophageal echocardiography, computed tomography and magnetic resonance imaging) have improved the diagnosis and the planning for surgery when a heart tumour is suspected or discovered. Benign cardiac tumours represent up to $75 \%$ of the cases. Surgical resection allows specification of the type of tumour in the majority of the cases.

No randomised clinical trials have been carried out to determine the optimal therapy for primary cardiac tumours. The prognosis for survival in patients with cardiac tumours varies from excellent after resection of myxoma to dismal when malignant neoplasms have been diagnosed. Surgery may be the treatment of choice for small malignant tumours localised to the heart. Partial resection of large neoplasms to relieve mechanical effects might be considered in exceptional cases, especially in children. Whilst total resection of cardiac sarcomas may occasionally appear feasible, most operations are palliative and performed to relieve cardiac compression or haemodynamic obstruction.
This paper reviews the most common benign and malignant cardiac tumours, summarises some interesting cases treated at our institution and gives an brief overview of our experience during the last 15 years.

Key words: cardiac tumours; surgical; resection; outcome

\section{Introduction}

Cardiac tumours include benign and malign neoplasms within the cardiac chambers and the myocardium, as well as metastatic diseases. Tumours of the heart, while uncommon, may become symptomatic through obstruction, embolisation (sometimes characterised by distant growth of viable embolic material), and constitutional manifestations (especially in cases of intracavitary tumours, for instance myxomas) [1-4]. Systemic tumour embolisation may occur as an initial manifestation but care must also be taken that this complication does not occur intraoperatively. Therefore, particular attention has to be paid to avoid tumour fragmentation during surgical exploration. The incidence of primary cardiac tumours in autopsies varies from $0.001 \%$ to $0.3 \%$, depending on the type of hospital, in which patients were hospitalised. There are numerous publications in the literature, showing that type and frequency of each tumour depends on whether the study was based on autopsy, surgical experience or reference centre material and whether they were performed in a paediatric or an adult population. Primary cardiac tumours arise from the three layers of the heart (pericardium, myocardium, and endocardium) as well as from the connective tissue within the heart [1]. In some instances, rare diseases are sometimes consid-

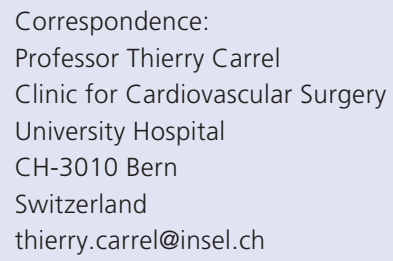


ered as cardiac tumours but are not really true neoplasms (hamartoma and heterotopia). Approximately $75 \%$ of cardiac tumours are benign, but they may have disabling or even lethal complications. Types of tumour are very different in adults and children, with a large majority of benign tumours being myxomas, lipomatous tumours, or papillary fibroelastomas, whereas the same incidence of tumours in young patients aged $<16$ years is rhabdomyomas, teratomas, and fibromas. The four most common malignant primary cardiac tumours in adults are: angiosarcoma, rhabdomyosarcoma, mesothelioma, and fibrosarcoma. Secondary cardiac tumours include metastases from extracardiac tumours disseminated via the blood or lymphatic system. Carcinomas and melanoma are the main source of cardiac metastases, followed by secondary haematologic malignancies (malignant lymphoma, multiple myeloma, and leukaemia) [5].

Due to the low incidence and the diversity in clinical presentation, the diagnosis of primary cardiac tumours may be missed or delayed. This may in part explain the morbidity and mortality associated with benign cardiac tumours. Systemic or pulmonary thromboembolism is one of the most common factors, occurring in about $60 \%$ of cardiac tumours. Cerebral embolism is common in left-sided tumours, and transient ischaemic attacks or strokes are not unusual first symptoms. In addition, left-sided intracavitary tumours may obstruct the mitral or aortic valve, whereas right-sided tumours are prone to obstruct the tricuspid or the pulmonary valve, thereby causing right cardiac failure and symptoms of obstructed right heart inflow, such as hepatomegaly, ascites and peripheral oedema. Intramyocardial tumours may cause arrhythmias and cardiac failure, while sudden death may be explained by the following mechanisms: arrhythmias, coronary obstruction or embolisation, tamponade cause by bleeding or effusion, and valvular obstruction.

Some tumours may cause unspecific general symptoms such as fever and fatigue as well as arthralgias and anaemia due to the release of tumour products such as interleukin-6, tumour necrosis factor or other neuroendocrine factors from the neoplastic tissue. Clinical examination is otherwise non-specific, however cardiac signs in patients who otherwise have no previous cardiac problems in association with general symptoms and embolic events should initiate cardiac investigation. Echocardiography is most often the first examination [6]. Magnetic resonance imaging generally allows a complete tumour diagnosis and planning of the operative procedure [7]. Surgery is indicated in the large majority of benign tumours and should be performed as soon as the diagnosis has been secured in order to avoid additional complications.

\section{Imaging and diagnosis}

Imaging plays a central role in the evaluation of cardiac tumours, and familiarity with their characteristic features is essential in order to generate a meaningful differential diagnosis. In the past, 2-dimensional transthoracic echocardiography and transoesophageal echocardiography have proved to be extremely valuable in the diagnosis of cardiac masses [8]. Nowadays, 3-dimensional transthoracic and transoesophageal echocardiography offers the cardiologist and cardiovascular surgeon the most accurate preoperative and intraoperative assessment of cardiac masses and correlates well with pathological findings [9]. However, sometimes anatomical and morphological information are incomplete. Real-time three-dimensional (3D) TEE is increasingly being used in general clinical practice. However, the use of real-time 3D TEE for the assessment of atrial myxomas has not been described to date. Tolstrup and colleagues recently described a series of ten patients with left atrial myxomas undergoing twodimensional and real-time 3D TEE. They were able to demonstrate that 3D imaging accurately identifies these tumours and provides detailed morphological description of the tumours, which may have clinical importance. In addition, because the $3 \mathrm{D}$ TEE is real time and can be performed preoperatively in the operating room, the surgeon may gain a complementary understanding of the nature and location of the tumour [9].

Beside echocardiography, cardiac magnetic resonance imaging has become the imaging modality of choice for evaluation of suspected cardiac masses [10]. The majority of the patients will have undergone an initial echocardiography. However, the latter exam suffers from several limitations: restricted field of view, incomplete assessment of an invading cardiac mass due to an unfavourable patient body habitus, and limited ability to perform tissue characterisation. The role of magnetic resonance imaging in this setting is well established because of its ability to obtain a wide field of view, generate high contrast and spatial resolution, and perform multiplanar imaging, allowing precise demonstration and localisation of a mass [7].

Furthermore, magnetic resonance imaging helps discriminate between a true cardiac mass and a pseudomass. In addition, tissue characterisation by magnetic resonance imaging may serve in generating a differential diagnosis, and can distinguish a cardiac neoplasm (which generally will require excision) from other conditions such as intracardiac thrombus, lipomatous hypertrophy or benign lipomas (all of which generally do not require excision). Finally, even when the aetiology of a mass remains known, magnetic resonance may provide useful information regarding tumour perfusion, invasiveness into cardiac or extracardiac structures and help to obtain tissue characterisation in selected cases [10]. Recently, computed 
tomography (CT) provides complementary information and, with the advent of electrocardiographic gating, has become a powerful tool in its own right for cardiac morphological assessment [11].

\section{Benign cardiac tumours}

\section{Cardiac myxoma}

Cardiac myxoma is the most frequent benign cardiac tumour. Myxomas account for more than 50\% of all primary cardiac tumours in adults. Their incidence is highest among women aged 40 to 60 [12]. Usually a myxoma is a left atrial intracavitary mass (80 to $90 \%$ ), originating from the septal surface of the left atrium, the roof and much more rarely close to the mitral valve anulus. More rarely, myxoma will grow in the right atrium or in the ventricles. In some rare cases, multiple myxomas may appear, these are usually familial and develop at a younger age than a single myxoma. A myxoma is a sessile or pedunculated, polypoid tumour with a smooth but friable surface which may produce emboli and sometimes has areas of haemorrhage. Patients with a myxoma often present with one or more of the most classical symptoms: heart failure due to obstruction, stroke due to embolism (observed in 30 to $45 \%$ of left-atrial myxoma), and constitutional symptoms (including fever, weight loss, or arthralgia) with inflammatory manifestations [12]. They may suffer from flow obstruction within a cardiac chamber (pulmonary or systemic venous drainage) or obstruction of the atrio-ventricular valves. In addition to obstruction, impairment of mitral valve closure caused by the vicinity of the tumour may lead to mitral valve regurgitation. An organised thrombus represents the most important diagnostic entity to be differentiated from a myxoma. Sometimes, a thrombus can be adherent to a myxoma, making the differential diagnosis particularly challenging [13]. In rare cases, mycoma can be attached to the mitral valve $[14,15]$ or be observed in children [16]. Surgical excision is indicated in every patient. The classical approach is performed through the left atrium (incision in the interatrial groove) for inspection of the attachment to the atrial wall or the atrial septum [17]. Then the right atrium is opened and excision can be performed under sight. While a majority of cardiac myxomas are definitively cured after surgical resection, a small proportion may exhibit a more malignant evolution, characterised by local invasion or metastatic growth of tumour emboli [18]. Myxoma may have a familial occurrence in about $5 \%$ of the patients. In this case, they are less common in the left atrium (only in up to 60\%), and are more often multiple (in up to $30 \%)$. Overall hospital mortality after removal of atrial myxomas should be less than $2-3 \%$. Virtually, all deaths occur in older age patients with severe comorbidities. Supraventricular arrhythmias are quite frequent after removal of atrial tumours. Recurrence is very rare and may be caused by incomplete excision or growth from a new focus [19].

\section{Case report 1: Benign myxoma}

A 55-year-old woman without significant previous disease presented to the general practitioner with a temperature of $37.5^{\circ} \mathrm{C}$, recurrent cough, progressive exertional dyspnoea and impaired functional capacity (NYHA class II). A new diastolic heart murmur was noted. Because symptoms were associated with an increased white cell count and elevated C-reactive protein levels, a possible diagnosis of infective endocarditis was considered. The patient underwent transthoracic echocardiography. A mobile solid left atrial mass was found, which seemed to be attached to the anterior mitral cusp. Surgical exploration was indicated. After induction of anaesthesia, transoesophageal echocardiography confirmed a large, hyperechogenic and pedunculated tumour with central echolucency. The tumour was attached to the base of the anterior mitral cusp between segments A1 and A2. During diastole, the mass

\section{Figure 1}

Large echolucent tumour with a broad attachment on the anterior mitral valve cusp and subvalvular mitral stenosis (A) with prolaps into the left ventricular outflow tract during diastole (B).

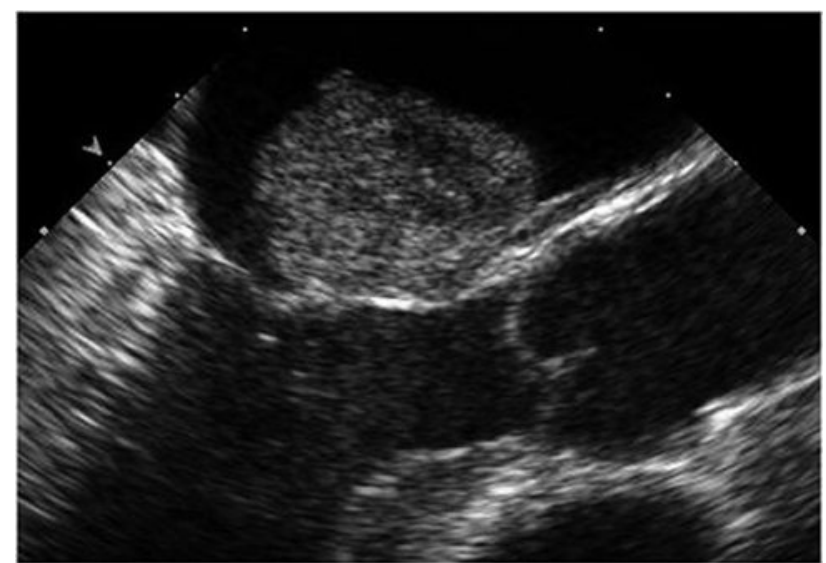

A

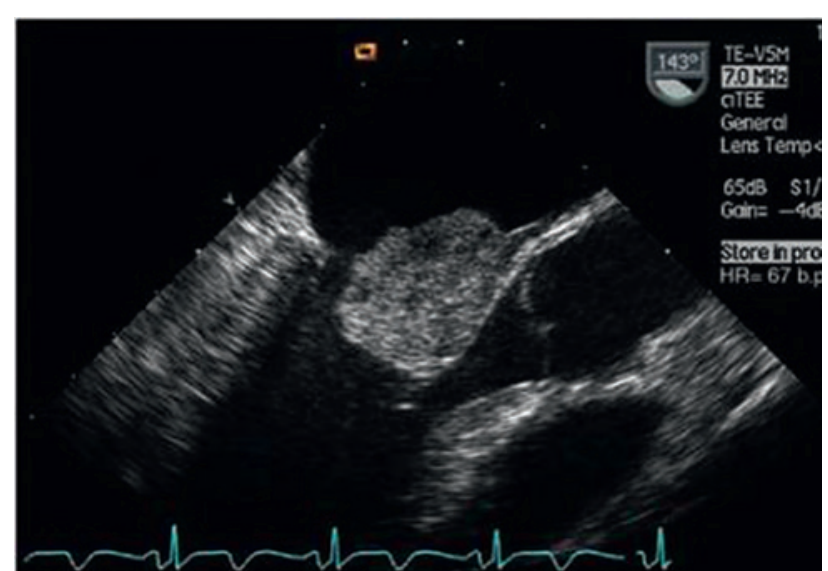

B 


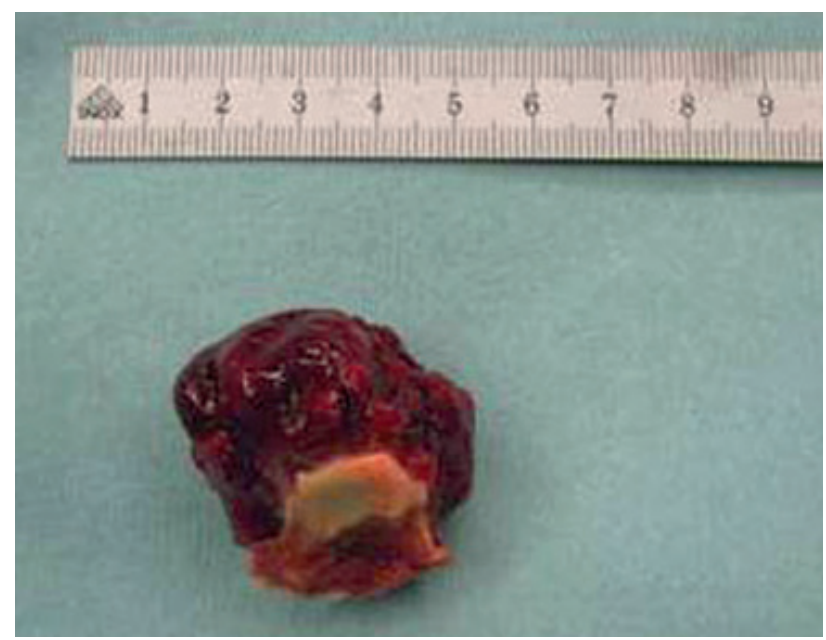

Figure 2

Radically excised large $(4-5 \mathrm{~cm})$ left atrial myxoma with part of the anterior mitral cusp. (Reproduced from [15]: Erdös G, Reineke D, Basciani R, Carrel T, Eberle B. Left atrial myxoma attached to the anterior mitral leaflet with symptoms suggestive of infective endocarditis. Eur J Echocardiography. 2010;11:E8, by permission of Oxford University Press, Oxford, United Kingdom.)

prolapsed into the left ventricle, obstructing a major portion of left ventricular inflow (fig. 1), which in addition caused a moderate mitral stenosis (functional valve orifice area $1.05 \mathrm{~cm}^{2}$; mean transvalvular gradient $10 \mathrm{~mm} \mathrm{Hg}$ ). Surgical exploration was performed through a transseptal approach to the left atrium. The tumour was found to be attached to the anterior mitral cusp and the roof of the left atrium. Complete resection of the tumour left a defect in the anterior A1 part of the mitral cusp (fig. 2). This necessitated reconstruction of the cusp with a patch of xenopericardium, and of the mitral annulus, which was performed using a $26 \mathrm{~mm}$ Physio-II annuloplasty ring from Edwards Lifesciences. Post operative histological analysis revealed a mesenchymal tumour with myxoid matrix without atypical cells or necrosis [15].

\section{Case report 2: Malignant myxoma}

A 31-year-old patient was admitted because of fever and exertional dyspnoea. He had suffered from a transient ischaemic attack with paresis of the left upper extremity prior to admission. Transthoracic echocardiography revealed the presence of a left atrial mass that was considered to be the source of the cerebral embolism. Surgery was performed through a combined left and right atrial approach [18]. A pedunculated tumour originating from the interatrial septum and prolapsing through the mitral valve into the left ventricle was removed with a generous portion of the interatrial septum. Closure of the interatrial septum was performed with a pericardial patch. The macroscopic aspect of the tumour was polypoid, multilobulate and friable, thus typical for a left atrial myxoma. The histological properties of the tumour differed somewhat from those of a more conventional myxoma. The tumour included a large amount of spindle and polygonal cells with polymorphic and hyperchromic nuclei and demonstrated a high mitotic rate. The postoperative course was uneventful and the patient was discharged from hospital one week after surgery. Two months later he suffered from generalised seizure. Computed tomography revealed multiple frontal and occipital bilateral cerebral metastases.

At this time, no recurrence was demonstrated within the heart. During the same hospitalisation, two soft tissue metastases - one located over the scapula and the other in the right gastrocnemius muscle - were resected. Histology of the resected metastases was consistent with that of the primary cardiac tumour. Complete staging of the patient demonstrated a further metastasis located in the lower lobe of the right lung. After irradiation of the cerebral metastases with a total dose of 5000 Gy and five courses of chemotherapy including adriamycine and ilosfamide the cerebral and pulmonary metastases disappeared completely and the patient still remained in complete remission six years after the initial resection of the atrial myxoma. However later the patient was lost to follow-up.

\section{Papillary fibroelastoma}

Papillary fibroelastoma is a rare cardiac tumour that was originally typically described at autopsy. Although cardiac papillary fibroelastoma is a benign tumour, it cannot be considered as harmless lesion, because systemic embolic events are frequent and primarily involve adults in their active period of life. Papillary fibroelastoma is the second most frequent cardiac tumour and represents approximately $7 \%$ of cardiac tumours $[12,20]$. Thanks to improved imaging modalities, such tumours are relatively easy to detect and therefore are actively searched in patients with unclear cerebral or systemic embolic events but frequently papillary fibroelastomas are discovered incidentally. Echocardiography must therefore consider fibroelastoma in the differential diagnosis of every unclear embolic event, especially because surgical resection is most often curative. At coronary angiography, fibroelastoma must be suspected in the presence of a mass near the coronary ostia or prolapsing into the left ventricular outflow tract [21]. Great care has to be taken because migration of further embolic materials may be facilitated by catheter manipulation. In particular, a papillary fibroelastoma must be considered when lysis or angioplasty do not restore a normal coronary flow (see case report below). Once the diagnosis is considered, immediate termination of coronary angiography is recommended. TTE can adequately screen for papillary fibroelastoma particularly when tumours are larger than $2 \mathrm{~mm}$ (sensitivity around 90\%). However, if feasible, TEE is the preferred method because of its high resolution and improved imaging capabilities, 


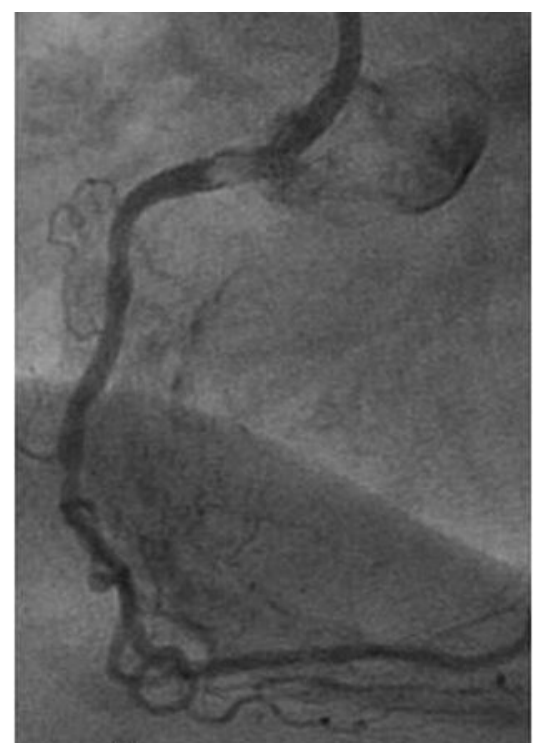

Figure 3

Coronary angiography (right coronary artery) showing a thrombus-like structure close to the right coronary ostium, involving the segment 1 of the right coronary artery. (Reproduced from: Frésard I, Stalder M, Gugger M, Goy JJ. Cardiac fibroelastoma causing angina. Eur H Journal. 2010;31:380, by permission of Oxford University Press, Oxford, United Kingdom.)

particularly in regard to small sized tumours. In the majority of cases, the following features are present: small lesion of about 9-12 $\mathrm{mm}$ in diameter, homogeneous, mobile and pedunculated mass located on one of the aortic valve cusps. Echocardiography may fail to differentiate papillary fibroelastoma from other cardiac masses such as tumours, thrombus, vegetation, valvular calcification, and Lambl's excrescence. The latter are frond like growths that occur only along the closure lines of cardiac valves, predominantly the aor- tic valve [12, 22]. In such cases, computed tomography or magnetic resonance imaging may be helpful. The ultimate diagnosis is usually made during operative resection and confirmed by histopathology.

\section{Case report 3: Fibroelastoma}

An 81-year-old woman presented with unstable angina and complained of chest pain during the last months. At coronary angiography, a thrombus was suspected in the proximal segment of the right coronary artery (fig. 3). Medical treatment using abciximab failed to reverse symptoms, as did angioplasty and stenting. During angiography, episodes of chest pain with inferior ST-segment elevation and hypotension occurred. Transthoracic echocardiography demonstrated the presence of a mass obstructing flow in the right coronary ostium (fig. 4). The patient was referred to surgery. Intraoperative transoesophageal echocardiography confirmed the ostial obstruction of the RCA by a mobile, 12 to $19 \mathrm{~mm}$ sized tumour located in the right coronary cusp of the aortic valve [23].

Surgical exploration was performed using standard cardiopulmonary bypass. A transverse incision was performed in the ascending aorta and the tumour, which was attached to the aortic cusp by a thin pedicle, was removed without damaging the aortic valve (fig. 5). A bypass graft to the distal right coronary artery using saphenous vein was performed. Weaning from cardiopulmonary bypass was uncomplicated and ischaemic ECG changes disappeared. The postoperative course was uneventful, and the patient was discharged home on the seventh postoperative day. Histopathological examination confirmed the diagnosis of papillary fibroelastoma (fig. 6).

A review of the recent literature using medical search engines (PubMed, Medline) identified five case
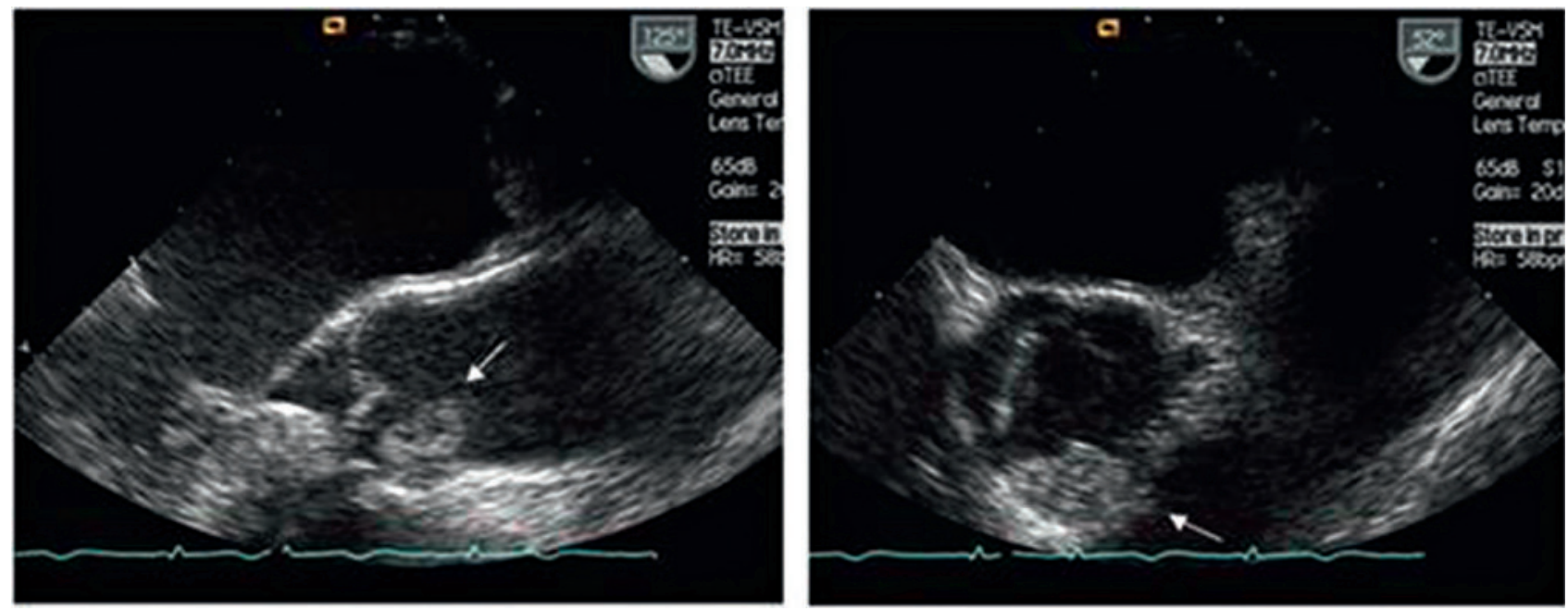

\section{Figure 4}

Echocardiography demonstrating the tumorous structure located in the right coronary cusp of the aortic valve. (Reproduced from: Frésard I, Stalder M, Gugger M, Goy JJ. Cardiac fibroelastoma causing angina. Eur H Journal. 2010;31:380, by permission of Oxford University Press, Oxford, United Kingdom.) 

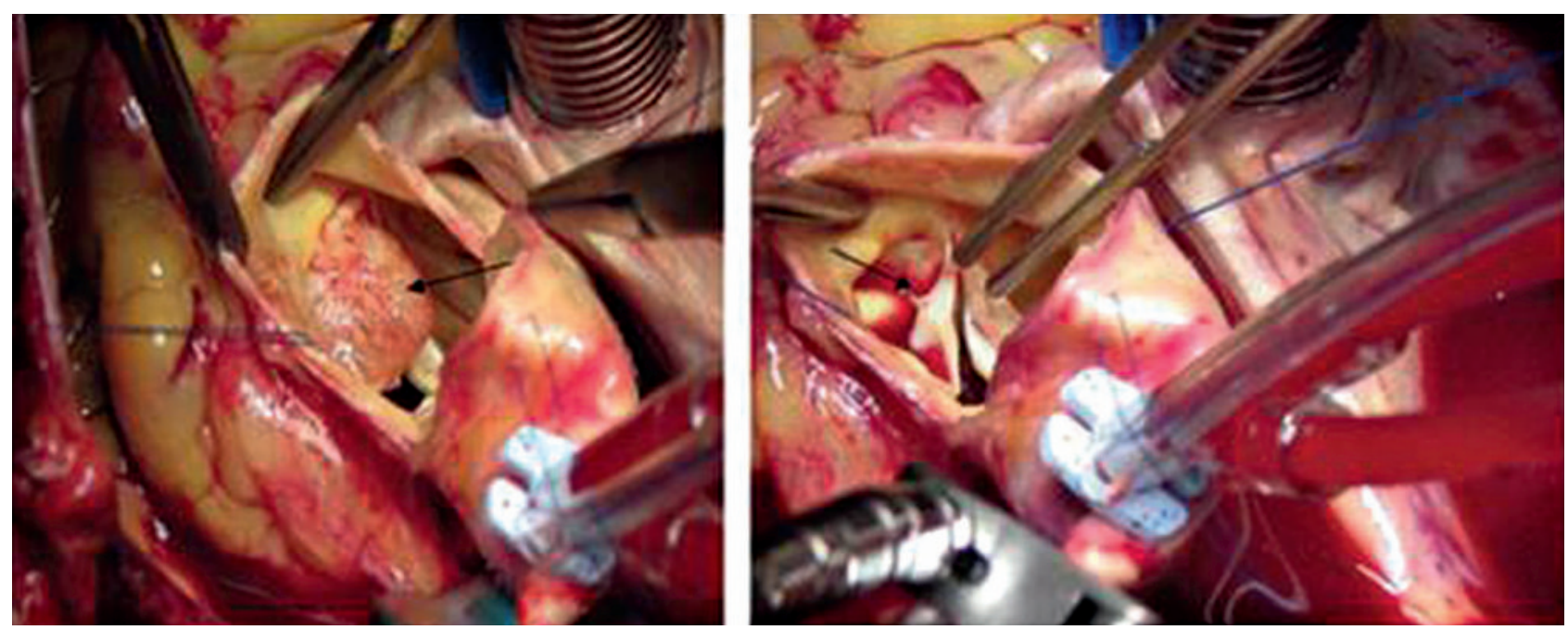

\section{Figure 5}

Intraoperative view after transverse aortotomy showing the papillary fibroelastoma largely filling the right coronary cusp (left) and after complete resection and before shaving the base of the tumour. The leaflet was not damaged and valve function was normal after the procedure. (Reproduced from: Frésard I, Stalder M, Gugger M, Goy JJ. Cardiac fibroelastoma causing angina. Eur H Journal. 2010;31:380, by permission of Oxford University Press, Oxford, United Kingdom.)

reports of coronary artery ostial occlusion caused by papillary fibroelastoma diagnosed during life [24]. Four patients presented with angina or myocardial infarction. One patient suffered primarily from embolic stroke due to a fibro-elastoma arising from the aortic wall, immediately next to the right coronary ostium. The RCA was involved in the majority of the cases except in one, in which the tumour was localised close to the commissure between left and non coronary sinus with partial obstruction of the left coronary ostium causing intermittent angina and syncope. All patients were diagnosed by echocardiography and referred to surgery. A complete surgical removal with bypass grafting of the affected coronary artery system was performed in all patients. Replacement of the aortic valve was necessary only in one case because of the broad base of the fibroelastoma on the aortic cusp, precluding a valve-sparing technique. However, in the large majority of cases, papillary fibroelastoma of the aortic valve can usually be "shaved" from the affected valve cusp or excised and the corresponding cusp reconstructed using a small piece of autologous pericardium.

\section{Rhabdomyoma}

Rhabdomyoma is the most common benign tumour in children (up to $50 \%$ of tumours seen in childhood) with a majority of the cases diagnosed at prenatal ultrasound or in the first year of life. The tumour originates from cardiac myocytes. In a substantial proportion of cases, it is associated with tuberous sclerosis. Rhabdomyomas are located more often in the ventricle with both sides equally involved rather than in the atrial wall. They can be small or protrude largely into the cardiac cavities $[12,25,26]$. Whether rhabdomyomas are true neoplasms or myocardial hamartomas is still controversial, the latter is generally considered to be more likely. Rhabdomyoma frequently present soon after birth or in the first weeks of life with severe cardiac failure.

Little is documented about the natural history of patients with cardiac rhabdomyomas. However, there are numerous reports which described spontaneous regression in number and size of these tumours. This is the reason why surgery is not routinely indicated. Patients with life-threatening complications (haemodynamic compromise due to valvular or ventricular outflow tract obstruction, recurrent hypoxic episodes or

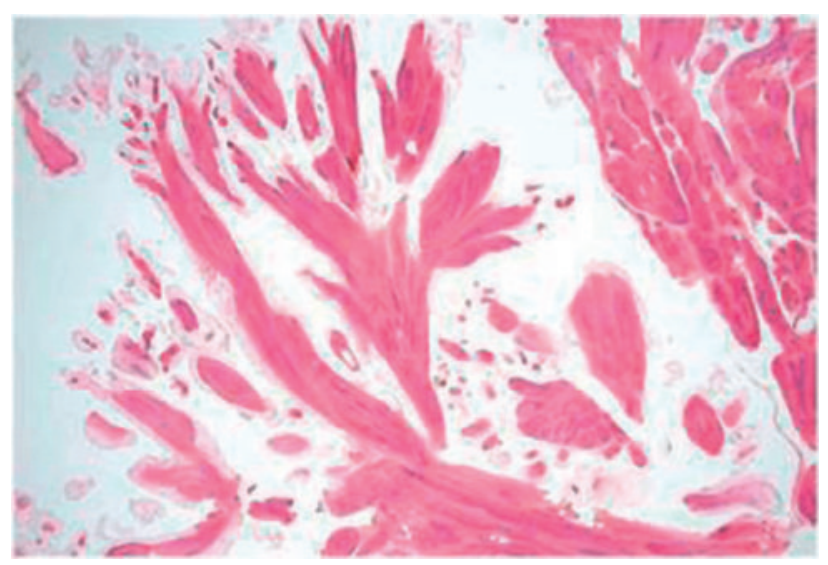

Figure 6

Typical histological preparation (haematoxylin-eosin) of the papillary fibroelastoma. The central avascular fibrous core is a characteristic finding as is the peripheral myxomatous zone and the outer rim of hyperplastic endothelial cells. Stains specific for elastin helps usually to correctly identify the tumour. (Reproduced from: Frésard I, Stalder M, Gugger M, Goy JJ. Cardiac fibroelastoma causing angina. Eur H Journal. 2010;31:380, by permission of Oxford University Press, Oxford, United Kingdom.) 


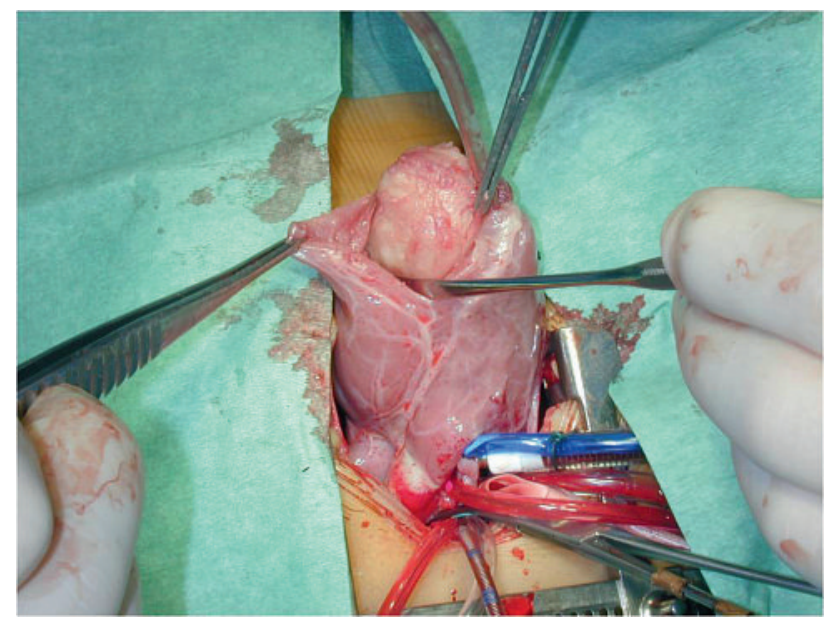

Figure 7

Excision of a large rhabdomyoma from the left ventricle in a neonate because of significant left ventricular outflow tract obstruction. Ventriculotomy at the level of the apex, tumour enucleation and closure of the LV with running suture using autologous pericardial strip for reinforcement. Note the close vicinity of the LAD.

refractory rhythm disturbances) are those who require surgical excision (fig. 7) [12]. Excision is limited to the area of the tumour and in some instances, only intracavitary resection is performed as the remaining intramyocardial portion may well regress spontaneously [26].

Degueldre and colleagues analysed the long-term cardiac and neurological outcome of 73 patients with cardiac rhabdomyoma in order to allow comprehensive prenatal counselling [27]. They analysed the number and location of the tumours to establish a potential association with a diagnosis of tuberous sclerosis. The presence of multiple cardiac tumours suggested a high risk of being affected by tuberous sclerosis [27]. Cardiac complications included arrhythmias, obstruction of the left ventricular outflow tract and secondary cardiogenic shock. The importance of the diagnosis of tuberous sclerosis was exemplified by the neurodevelopmental complications, with $80 \%$ of the patients developing epilepsy, and 66\% suffering from delayed mental and psychological development. The tumours usually regress after birth and cardiac-related problems are rare after the perinatal period.

\section{Fibroma}

Cardiac fibroma is another common benign tumour of the heart in children. They account for up to $10 \%$ of the cases. Fibromas are solitary tumours that grow predominantly in the anterior wall of the left ventricle or into the interventricular septum. As the name indicated, the tumour is made of fibroblasts with a variable amount of collagen and elastic fibres. There is an association of cardiac fibroma with basal cell naevus syndrome (Gorlin) [28], which is characterised by multiple nevoid basal cell carcinoma of the skin. Patients with fibroma may become symptomatic with heart failure, ventricular arrhythmias and sudden death, although one third of the patients remain asymptomatic and tumour is detected incidentally $[12,28]$. In symptomatic cases, the tumour can be enucleated from the ventricular wall, when the tumour is very large, and complete resection seems impossible, partial resection may result in good palliation [25, 29, 30]. Exceptionally, cardiac transplantation may be required when large and extensive tumour involvement precludes complete excision [12, 29].

\section{Case report 4: Cardiac fibroma}

A 14-months-old boy who suffered from loss of weight and increasing dyspnoea was referred for general examination. Cardiac auscultation revealed a systolic murmur and transthoracic echocardiography showed a $40 \times 25 \mathrm{~mm}$ tumour with the basis located at the anterior wall of the right ventricle. The tumour practically filled the cavity of the right ventricle and extended up to $10 \mathrm{~mm}$ below the pulmonary valve. Elective surgery was performed and the tumour resected from trans-tricuspidal and transventricular. The tumour was located in the ventricular wall and after enucleation (fig. 8), the endocardial layer was sutured to the epicardium to avoid intraparietal haematoma formation. A Gore-Tex patch was necessary to close the defect left in the anterior wall of the right ventricle. The postoperative follow-up was uncomplicated, the histology was typical for a cardiac fibroma. Follow-up echocardiography after three and twelve months showed normal intracardiac findings. Three years after surgery the child is doing well without tumour recurrence [31].

\section{Other rare cardiac tumours and tumour-like conditions}

Primary cardiac haemangioma is an infrequent benign neoplasm which accounts for about $2 \%$ of all resected primary cardiac tumours [12, 32, 33]. The tumour is usually sporadic and may occur in patients of all age categories [34]. Haemangioma may cause pericardial effusion, congestive heart failure or arrhythmias. Rarely it affects the valve cusps.

Lipoma is very rate but may occur anywhere in the heart with a predilection for the pericardium and the interatrial septum [12]. This type of tumour remains usually asymptomatic and is found incidentally by routine echocardiography, most frequently in younger patients. Lipomatous hypertrophy of the interatrial septum may be considered as a subform of lipoma. It is weakly associated with obesity and usually affects older individuals [35].

The calcified amorphous tumour of the heart most frequently represents a partially calcified intracavitary mural thrombus [12], located most frequently in the ventricular cavities and more rarely in the atria or on the valves. There is an association of this finding with patients suffering from chronic renal failure, 


\section{Figure 8}

Echocardiography showing a large tumour into the right ventricle $\left(^{*}\right)$ with the attachment (arrow) at the anterior wall of the ventricle (A). Cardiac MRI confirmed the location of the tumour and showed that the tumour was largely floating in the right ventricle without any adhesions to the ventricular wall or the tricuspid valve. The tumour extended up to the right ventricular outflow tract (B). Intraoperative view after opening the anterior wall of the right ventricle (C). The endocardium and the epicardium were readapted after enucleation of the tumour. * shows the small transmural defect left at the site of the origin of the tumour to achieve complete resection (D). Reproduced with permission from Swiss Medical Forum. 2009;14:286-7.)
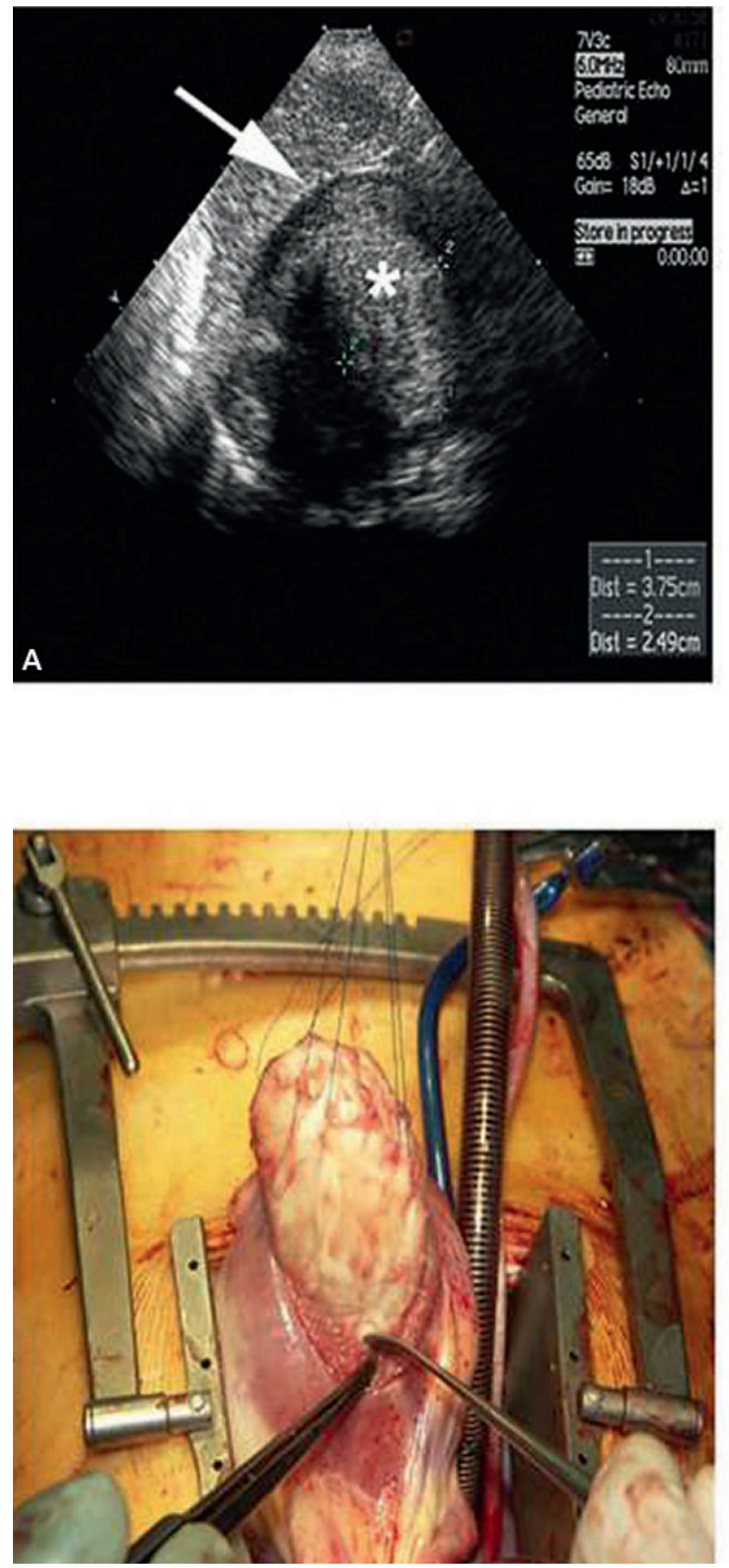

C

which may explain the severe calcification of the thrombus [36, 37]. Patients with a calcified thrombus may present with peripheral embolisation or other disastrous arterial occlusion [38].

Mural thrombus in the heart can mimic cardiac tu-
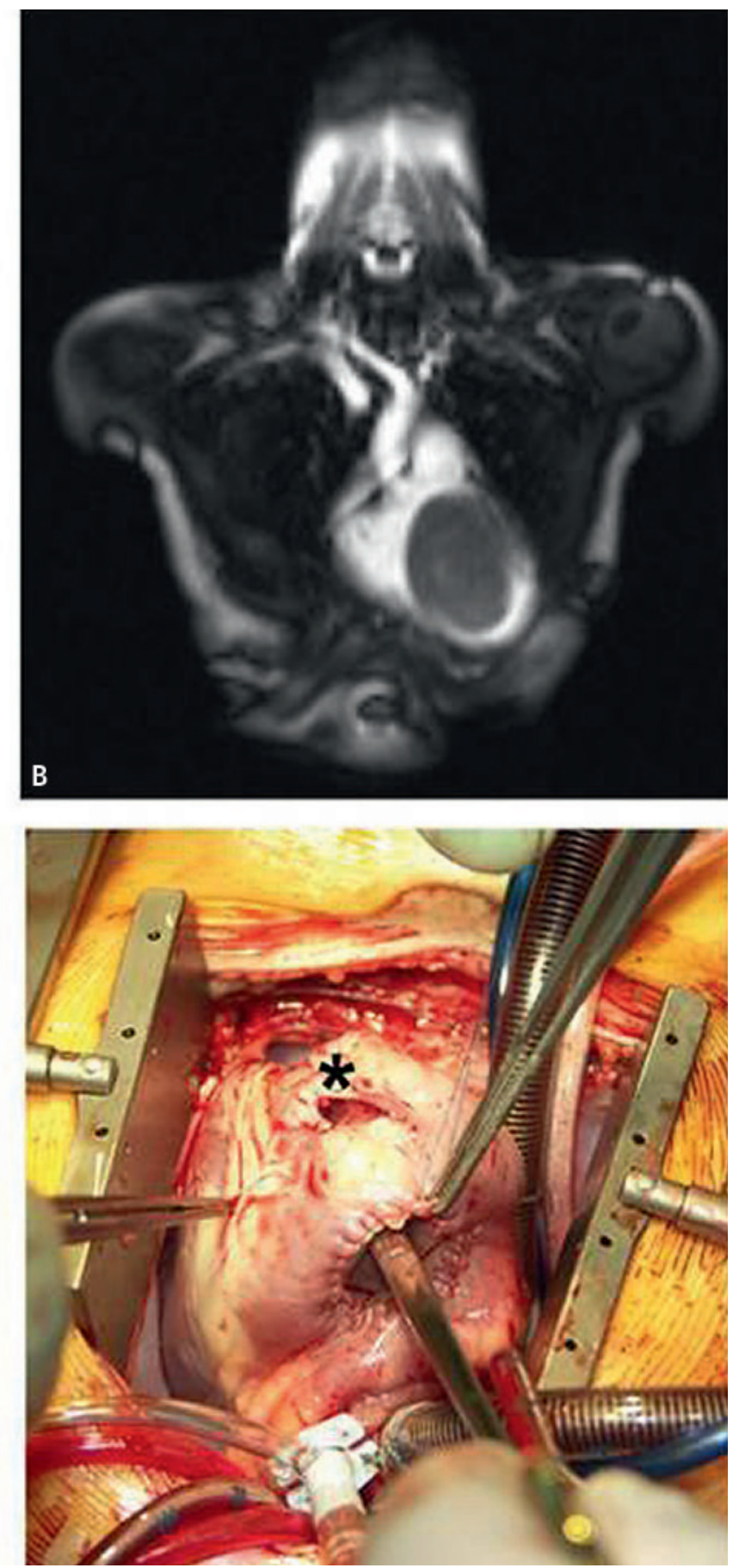

D

mour. Intracardiac thrombus may be located in the ventricular or atrial cavities. When left-sided, they are a common cause of stroke or peripheral arterial embolism. Thrombus of the right-heart side are detected in patients with pulmonary embolism [39]. In most cases, 
Figure 9

Large tumour thrombus in a 28 years old male patient - most probably following chronic drug abuse, extending from the apex of the left ventricle into the left ventricular outflow tract (A) and obstructing the aortic valve during systole (B).

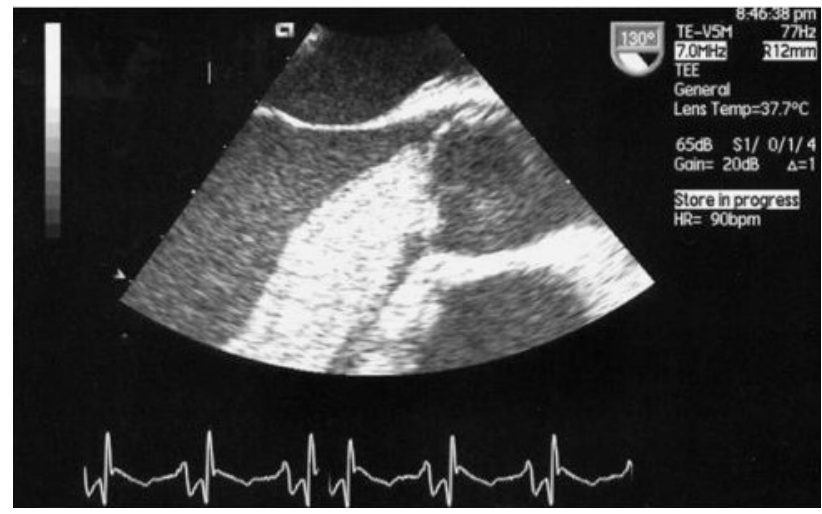

A

the diagnosis of a cardiac thrombus is incidental and the majority of patients are asymptomatic [12]. The most frequent aetiology of cardiac thrombi are myocardial infarction and dilated cardiomyopathy (left ventricle), mitral valve disease and chronic atrial fibrillation (left atrium), whereas chronic abuse of anabolic steroids or cocaine (fig. 9) and systemic diseases (chronic rheumatic diseases, coagulation disorders) may cause intracardiac thrombus in any of the cardiac chambers $[40,41]$.

\section{Malignant cardiac tumours}

Malignant primary tumours consist of primary cardiac sarcomas, the most common type of cardiac tumour after myxoma [42]. Angiosarcoma represent approximately $35 \%$ of the malignant cardiac sarcoma. They occur in younger adults, usually originate from the atrial wall and may extend into the afferent veins (pulmonary veins when located in the left atrium, superior or inferior vena cava when located in the right atrium) as well as into the corresponding atrio-ventricular valve. In rare instances, angiosarcoma may develop within the wall of the pulmonary artery or the vena cava, close to the heart $[42,43]$. Rhabdomyosarcoma account for about $5 \%$ of cardiac sarcoma and derived from the striated muscle. Usually, rhabdomyosarcoma are large and grow into the myocardium but may also protrude into a ventricular cavity $[42,44]$. Complete excision is rarely possible. Some patients are explored because the diagnosis is not clear before surgery, in others, surgical exploration allows tumour debulking. In these cases, adjuvant chemotherapy or radiotherapy may prolong life.

A retrospective study of primary cardiac tumours by Meng and colleagues showed that in histopathological differentiation about $80 \%$ of primary cardiac tumours were benign [45]. Among 31 cases with malignant tumours unclassified sarcoma (23\%), angiosar-

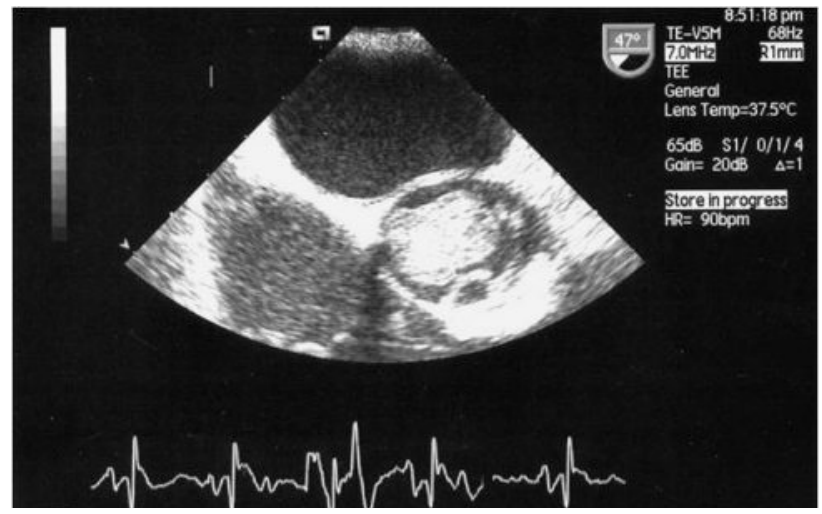

B

coma (19\%) and rhabdomyosarcoma (19\%) were the most frequent histological types of primary cardiac malignancies. Both, in myxomatous benign tumours and in primary malignant cardiac tumours the most common site of origin was the atrium. However, involvement of the pericardium was significantly higher with malignant tumours (26\% vs $0 \%, \mathrm{p}<0.05)$ [4]. CT-scan and MRI is especially helpful in tissue characterisation and in defining the extent to which the cardiac tumour infiltrates surrounding structures [46]. FDG-PET is helpful in order to determine the dignity and existence of peripheral metastases before undergoing surgery [47]. Llombart-Cussac analysed 15 patients with primary cardiac sarcoma who underwent primary surgery and received a doxorubicin regimen within six weeks of surgery and adjuvant chemotherapy [48]. Twelve of the 15 patients died after a median overall survival of 12 months. The 2 -year survival rate was $26 \%$, but survival was significantly longer for patients following radical resection (22 vs 7 months).

\section{Angiosarcoma}

\section{Case report 5: Poorly differentiated angiosarcoma}

A 49-year-old man presented with chest pain and shortness of breath. Laboratory showed elevation of D-dimers, but infection parameters were normal. CT scan of the chest excluded pulmonary embolism, but revealed an infiltration of the right basal pulmonary lobe and pleural effusion. A mediastinal mass, located close to the right atrium, was detected and confirmed by transthoracic echocardiography. Pneumonia was treated with amoxicillin/clavulanic acid and clarithromycin. Symptoms ameliorated significantly but soon after the patient experienced another episode of chest pain. Chest X-ray and CT-scan, again showed a density in the right basal pulmonary lobe, a significant right pleural effusion and prominent mediastinal lymph nodes. Contrast enhanced cardiac magnetic resonance 
imaging showed a retrocardial mediastinal mass of $7.4 \times 4 \mathrm{~cm}$ with compression of the right atrium and ventricle. Coronary angiography documented a strong vascularisation of the tumour originating from the right coronary artery. The FDG 18 uptake in positron emission tomography was increased in the mediastinum and in the region of the presumptive tumour without evidence of distant metastases. The interdisciplinary tumour board found surgery to be indicated. The tumour was resected, including the lateral wall of the right atrium, the adjacent pericardium and the visceral pleura. The free wall of the right atrium was reconstructed using a xenopericardial patch. Pathological examination revealed a spindle cell neoplasia with solid and papillary growth, including immature blood vessels lined by tumour cells and disseminated necrosis. Immunohistochemical staining was positive for vimentin, CD31, CD34 and sporadic for factor VIII, indicating that the tumour cells were derived from the endothelium. These findings allowed the diagnosis of a poorly differentiated angiosarcoma. The patient received chemotherapy with farmorubicin and haloxan, started two weeks after surgery.

Early diagnosis and radical excision are essential to long-term survival for primary cardiac sarcoma and can lead to long term survival, although this is rarely accomplished and overall results are very disappointing.

Orthotopic cardiac transplantation is a controversial treatment for primary cardiac sarcoma, but has been associated with prolonged survival in selected cases [49-51]. Cardiac transplantation for unresectable tumours has been described, although its use is limited by possible explosive recurrence postoperatively probably related to immunosuppressive therapy. In fact, the best option for very carefully selected patients theoretically remains orthotopic cardiac transplantation. It must integrate the resulting immunosuppressive therapy as a prognostic factor of local relapse and distant metastases. In contrast, local extension, such as pericardial location may not exclude the possibility of transplantation. Although long term survivors are known to be extremely rare, the limited experience reported by some authors in the literature confirms that heart transplantation, including in some cases a local pericardial and pleural resection, may be consistent with long term survival without relapse [49]. Despite the usual admittedly dismal prognosis related to the development of local or distant recurrence, cardiac transplantation can be mainly proposed for selected patients with no vascular cardiac sarcoma and no obvious distant metastases. Local and limited extracardiac extension (e.g.,pericardium) may not be considered as definitive contraindications but require additional surgical resection.

\section{Intracardiac extension of infradiaphragmatic malignant tumours}

Infradiaphragmatic tumours extending through the inferior vena cava into the right atrium or the right ventricle do not usually lead to specific cardiac symptoms and are found by echocardiography or computed tomography during staging of the primary abdominal tumour. The most frequent tumours are the Wilms tumours in children, hypernephroma, hepatocarcinoma and uterine leiomyosarcoma in adults [52, 53]. Natural history is not known but presumably right atrial extension worsens the prognosis associated with the primary tumour. In the last 15 years, we operated on 12 adult patients presenting with renal cell carcinoma extending into the inferior vena cava and through the tricuspid valve into the right ventricle. Successful total removal was performed through a midline laparotomy and median sternotomy or through thoraco-phrenicolaparatomy with the aid of normothermic cardiopulmonary bypass (fig. 10). An aggressive therapeutic approach requiring operations of escalating magnitude and multidisciplinary surgical treatment was sometimes controversially discussed but could help salvage patients who otherwise would not have been considered for operation [52]. During the same time period, seven children were operated upon for a Wilms tumour with extension into the inferior vena cava and the right atrium. They underwent a similar procedure, with cardiopulmonary bypass in three cases and with a venoatrial shunt being used during tumour extraction and reconstruction of the subhepatic inferior vena cava in two cases.

No perioperative mortality was observed in these patients, independently of the magnitude of these operations; mid-term survival - five years - was very satisfying with a tumour recurrence in $20 \%$ of the patients.

Nesbitt and co-authors analysed their experience with 37 patients suffering from renal cell carcinoma and inferior vena cava tumour thrombus who underwent surgical resection between 1989 and 1996 [54]. The 27 men and 10 women had a median age of 57 years. Distant metastases were present in 12 patients. Tumour thrombi extended to the infrahepatic inferior vena cava $(n=16)$, the intrahepatic inferior vena cava $(\mathrm{n}=16)$, the suprahepatic inferior vena cava $(\mathrm{n}=3)$, and into the right atrium $(n=2)$. All tumours were resected by inferior vena cava isolation and, when necessary, extended hepatic mobilisation, with primary or patch closure of the vena cavotomy. Cardiopulmonary bypass was necessary in only two patients with intraatrial thrombus. Complications occurred in 11 patients, and one patient died two days postoperatively of a myocardial infarction (mortality, 2.7\%). Overall 2and 5-year survival rates were $61.7 \%$ and $33.6 \%$, respectively. For patients without lymph node or distant metastases (stage IIIa), 2- and 5-year survival rates 


\section{Figure 10}

MRI of a patient with a renal carcinoma extending with a tumour thrombus into the inferior vena cava and through the tricuspid valve up to the right ventricle (A). Right atriotomy and excision of the tumour thrombus (B). Pathological specimen following radical excision (C).

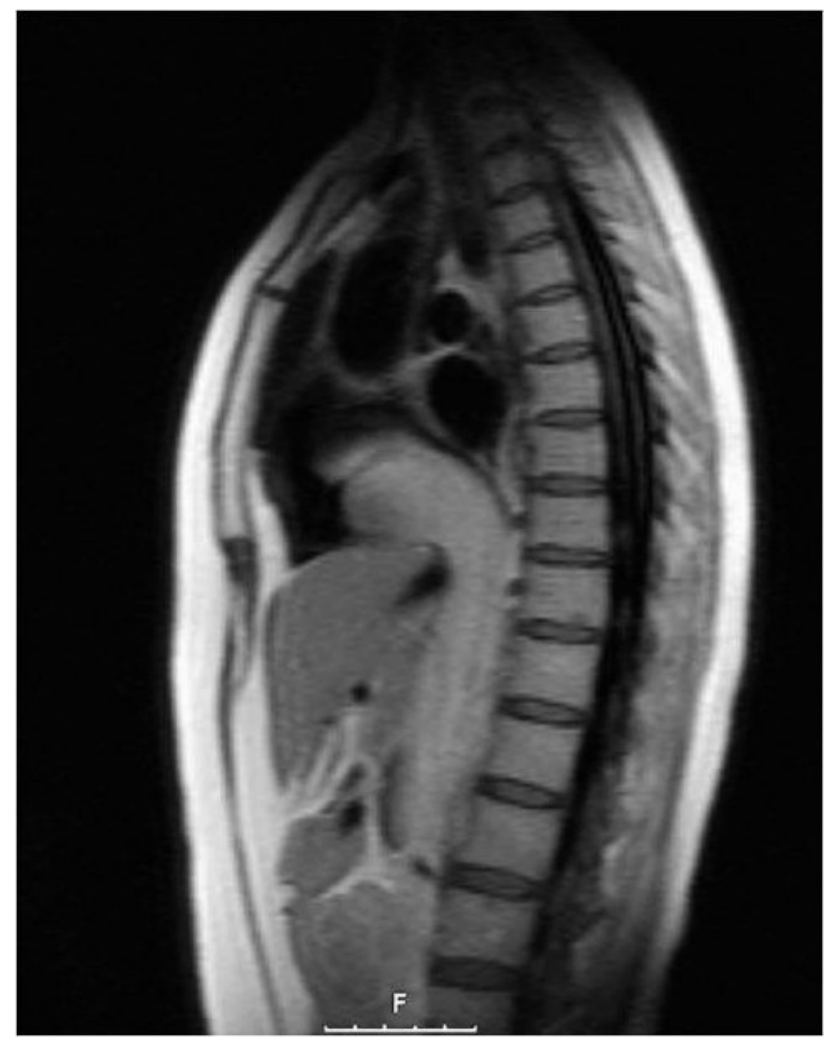

A

were $74 \%$ and $45 \%$, respectively. The presence of distant metastatic disease (stage IV) at the time of operation did not have a significant adverse effect on survival, as reflected by 2- and 5-year survival rates of $62.5 \%$ and $31.3 \%$, respectively. Lymph node metastases (stage IIIc) adversely affected survival as there were no long-term survivors. The authors concluded that resection of an intracaval tumour thrombus arising from renal cell carcinoma can be performed safely and results in prolonged survival even in the presence of metastatic disease. In their experience, extracorporeal circulatory support was required only when the tumour thrombus extended into the heart.

Endometrial stromal sarcoma (ESS) represents $0.2 \%$ of all uterine malignancies. Based on the mitotic activity, a distinction is made between low and highgrade ESS. Although the overall five-year survival rate for low grade ESS exceeds $80 \%$, about $50 \%$ of the patients show tumour recurrence, mostly after a long latency period. Tumour invasion of the great vessels is extremely rare but may occur and invade the inferior vena cava up to the right cardiac cavities.

A review of the literature identified 19 patients, including our own observation (see below), with advanced

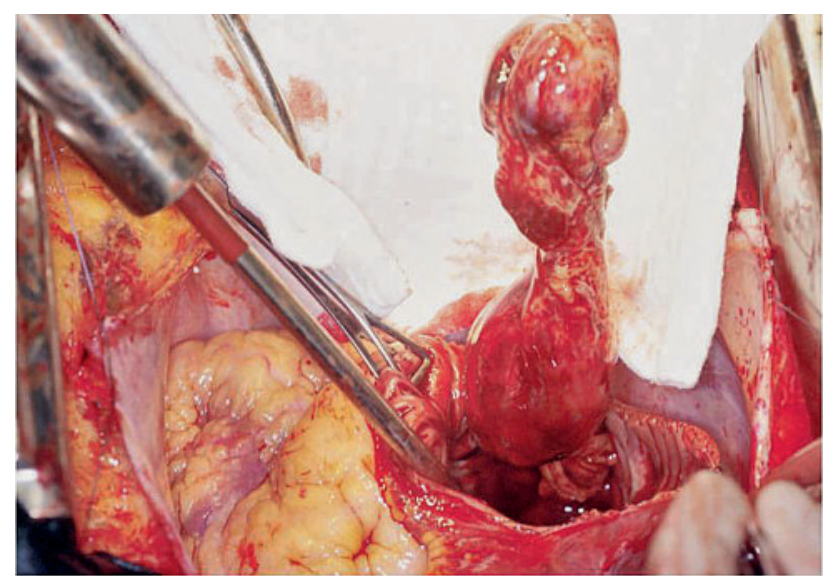

B

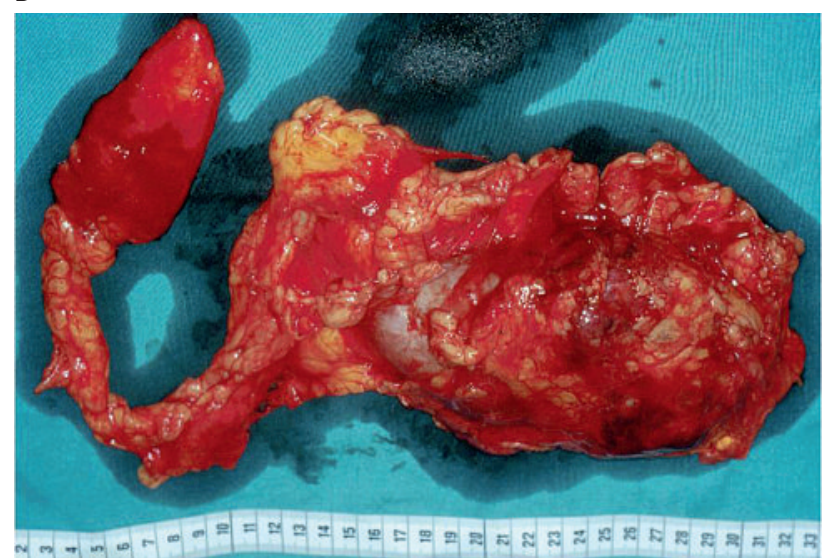

C

low grade ESS with invasion of the great vessels and a tumour thrombus in the inferior vena cava [55]. All patients presented with an abdominal tumour and a thrombus protruding into the inferior vena cava. The tumour thrombus extended into the right heart cavities in nine patients reaching the right atrium in four, the right ventricle through the tricuspid valve in three and the pulmonary artery in two patients. Five patients had advanced primary tumour and 14 suffered from advanced recurrent tumour. Seven patients presented with synchronous metastatic disease and six patients with a pelvic tumour infiltrating the bladder, the rectosigmoid colon or the infrarenal aorta. Median age at surgery was 47 , ranging from 25 to 65 years). Tumour thrombectomy was performed by cavatomy or by right atriotomy under normothermic, beating heart cardiopulmonary bypass. There was no peri-operative mortality and a very low morbidity. Radical tumour resections were achieved in ten patients. The follow-up for these ten patients was median 2 years, ranging up to 4.5 years. Nine patients showed absence of, whereas one patient suffered, an asymptomatic local recurrence.

Most authors claimed that resection of an inferior 
vena cava tumour thrombus, even with extension into the right heart cavities, can be performed safely. Extensive radical surgery is therefore justified in the treatment of advanced tumour manifestations of a low grade ESS, potentially improving recurrence free survival.

\section{Case report 6: Endometrial stromal sarcoma with extension into the right heart}

A 47-year-old female patient suffered from a low grade endometrial stromal sarcoma (ESS), a rare angioinvasive tumour with a high recurrence rate. She complained of fatigue, shortness of breath and abdominal pain in September 2003. The past history included excision of a malignant melanoma on the left leg in 1974, and abdominal hysterectomy because of a myomatous uterus with leiomyoma in 1993. CT-scan demonstrated a retroperitoneal mass and biopsy revealed a low grade ESS. Preoperative MRI demonstrated a large retroperitoneal tumour with infiltration of the infrarenal aorta and the inferior vena cava. Moreover, there was a large tumour thrombus within the inferior vena cava which extended into the right atrium. Because of the intracardiac tumour thrombus, the patient was judged to be at a high risk for acute heart failure and tumour embolisation into the lungs. At the multidisciplinary tumour board, extensive surgical resection was recommended to achieve the most complete tumour clearance. Approach was performed through a median sterno-laparotomy. The tumour was mobilised, then cardiopulmonary bypass was instituted following ascending aortic, superior vena cava and right external iliac vein cannulation. En-bloc resection of the retroperitoneal tumour was performed with resection of the infrarenal aorta and of the anterior wall of the inferior vena cava. The infrarenal aorta was reconstructed using a straight

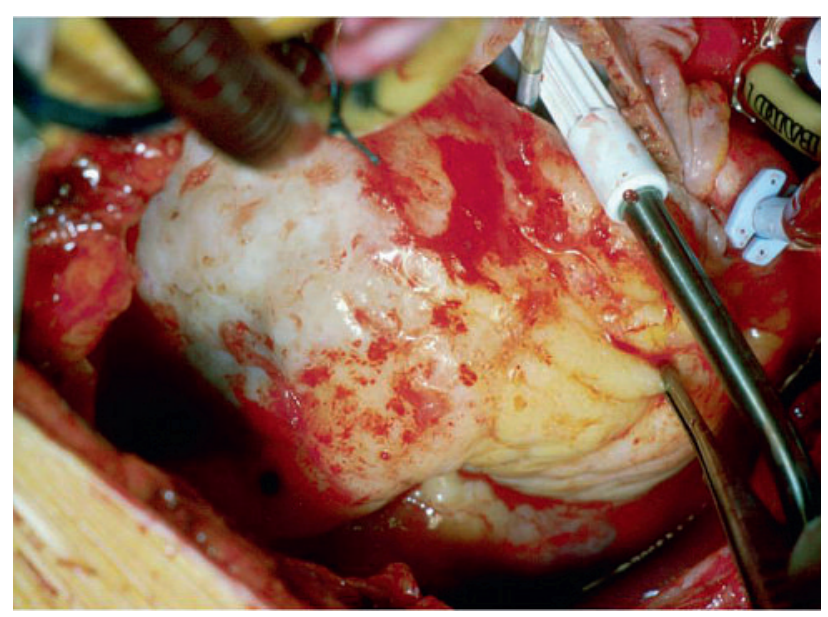

\section{Figure 11}

Large plasmocytoma metastasis located at the level of the atrio-ventricular groove and invading the right atrium with consecutive severe tricuspid stenosis. Tumour debulking only was performed with reconstruction of the atrial wall using xenopericardium. graft. The infradiaphragmatic vena cava and the right atrium were opened. Complete extraction of the intracardiac tumour thrombus was possible, since there were no adhesions to the wall of the vena cava or the right atrium. Reconstruction of the inferior vena cava was performed using xenopericardium. Applicators for postoperative brachytherapy were implanted in the iliac region and between the aortal graft and the reconstructed inferior vena cava. The postoperative course was uneventful.

Follow-up examinations were carried out every six months. CT scans of the thorax, abdomen and pelvis showed no signs of tumour recurrence but seven years after the operation, she developed a recurrence at the level of the hepatic vein drainage into the inferior vena cava. Apart from occasional and unspecific abdominal discomfort, the patient reports very good health with a complete return to normal activities [55]. Radical resection was performed very recently again using cardiopulmonary bypass to control the retrohepatic vena cava.

\section{Metastatic heart disease}

Secondary malignant cardiac tumours are found at autopsy in 10-15\% of patients with metastatic cancer disease. Cardiac metastases are among the least known and highly debated issues in oncology, and few systematic studies are devoted to this topic. The heart can be affected by any malignant neoplasm able to spread to distant sites. In general, cardiac metastases are considered to be rare. However, when sought for, the clinical incidence seems to be not as low as expected, ranging from $2.3 \%$ and $18.3 \%$. Although no malignant tumours are known that diffuse preferentially to the heart, some do involve the heart more often than others, for instance, breast and lung cancer, melanoma, plasmocytoma and mediastinal primary tumours [5658]) (fig. 11). Tumourous involvement of the pericardium is quite common and causes pericardial effusion, carrying the risk of tamponade.

Secondary cardiac involvement may be overlooked in the constellation of symptoms associated with metastasis but it usually occurs at the terminal phase of a prolonged disease course, especially in the setting of widespread metastatic disease [59, 60].

In the specific instance where secondary cardiac involvement leads to the initial diagnosis of malignancy, or is the first evidence of small volume metastatic recurrence, aggressive surgical management may result in long term survival, provided that all gross tumour can be excised [59, 60]. Surgery would be expected to be most beneficial in patients whose primary tumour is under control and who have a significant disease-free interval between control of the primary tumour and detection of the cardiac metastasis. In patients with recurrent pericardial effusion, simple or multiple punctions may be helpful, other patients 
are best treated by creation of pleuro-pericardial window through a thoracoscopy or pericardio-abdominal window through a small subxyphoidal approach.

It is not known whether adjuvant chemotherapy is beneficial in patients who have undergone curative surgery. Chemotherapy is the treatment of choice for cardiac neoplasms that have metastasised. The role of radiation in the treatment of cardiac tumours is not well defined [60]. Although radiation is the therapy of choice for malignant lymphomas, when combined with chemotherapy, it significantly increases the risk for myocardial and pericardial damage.

\section{Carcinoid heart disease}

Malignant carcinoid syndrome is a group of symptoms associated with carcinoid tumours from the gastrointestinal system arising from cells which produce large amounts of serotonin. The syndrome is characterised by flushes, diarrhoea and bronchospasms. Carcinoid heart disease is a manifestation of malignant carcinoid syndrome in which a unique form of fibrosis affects the endocardium, predominantly of the right heart cavities. Most patients have pathologic lesions limited to the tricuspid and pulmonary valves. The fibrous deposits lead to constriction of the valve annulus and adherence of the valve cusps to the right ventricular endocardium (tricuspid valve) or the pulmonary artery wall (pulmonary valve). A large majority of patients with carcinoid heart valve lesions suffer from hepatic metastases from the primary intestinal tumour. In echocardiography, the valve cusps are shortened and thickened and most patients show moderate to severe tricuspid regurgitation [61].

Progress in the medical and surgical management of patients with carcinoid disease has resulted in improved palliation and survival. Limited medical treatment options are available for patients with symptomatic carcinoid heart disease. Patients with severe carcinoid heart disease are currently referred for cardiac operation when they develop cardiac symptoms, ventricular dysfunction, or (rarely) in anticipation of hepatic surgery. Surgical outcome depends on patient age and functional class at the time of cardiac surgery. Despite metastatic disease that limits longevity, cardiac surgical survivors usually demonstrate dramatic improvement in functional capacity. Cardiac surgery should be considered early for patients with symptomatic carcinoid heart disease and controlled carcinoid symptoms. An experienced medical, surgical and anaesthetic team approach to the patient with carcinoid heart disease is critical in order to provide state of the art management.

Perioperative management of patients with carcinoid heart disease may challenge the anaesthetist because of two problems: carcinoid crisis and low cardiac output secondary to right ventricular failure. Carcinoid crises may be precipitated by the administration of catecholamines and histamine-releasing drugs. The group from Mt. Sinai Hospital, NY analysed a series of 11 patients with severe symptomatic carcinoid heart disease who underwent multivalve surgery (rightsided valves, $\mathrm{n}=8$; right- and left-sided valves, $\mathrm{n}=3$ ) between 2001 and 2007 [62]. All patients received octreotide intraoperatively [650 (300-1050) $\mu \mathrm{g}$ ] to prevent carcinoid symptoms and vasoplegia. Those patients on a higher preoperative octreotide regime required additional intraoperative octreotide (range) dose 300-850 vs 650-1050 $\mu \mathrm{g}$. Similarly, the use of larger doses of aprotinin (>5 KIU) was associated with higher requirements for octreotide. Catecholamines were generally required in those patients who presented with a worse New York Heart Association functional class. Overall mortality was $18 \%(n=2)$ and only one episode of mild intraoperative carcinoid crisis was observed. The authors concluded that carcinoid crisis and right ventricular failure still remain the primary challenges for the anaesthetist while managing patients with carcinoid heart disease. The study supports the administration of catecholamines to wean patients off cardiopulmonary bypass, particularly in the presence of myocardial dysfunction. Those patients on higher octreotide dosages required close intraoperative glucose monitoring. Earlier patient referral and more comprehensive perioperative management may improve the results in these critically ill patients.

Tricuspid and pulmonary valve replacement rather than repair may provide some palliation, but perioperative mortality is described as high as $20 \%$ [63, 64]. In a series published in 2011, Dreyfus and colleagues analysed 22 patients with carcinoid heart disease undergoing cardiac valve surgery [65]. Three patients underwent tricuspid valve replacement alone, 15 patients underwent tricuspid and pulmonary valve replacement, two patients underwent tricuspid, pulmonary and mitral valve replacement and two patients underwent quadruple valve replacement. Overall 30-day-mortality was $18 \%$. Cause of death was right ventricular dysfunction (two), refractory carcinoid crisis (one) and pneumonia (one). Four patients required a permanent pacemaker for complete heart block. Of those who survived initial surgery, median follow-up was 26 months (interquartile range 8-42); one- and two-year survival rates were $56 \%$ and $44 \%$, respectively. The authors found no significant difference in survival between those patients in the New York Heart Association (NYHA) class I/II, mild/moderate right ventricular dilatation or $\mathrm{N}$-terminal brain natriuretic peptide (NT-proBNP) <1245 pgml (-1) compared with those in NYHA class III/IV, severe right ventricular enlargement or NT-proBNP >1245 pgml (-1), respectively. Long term causes of death were related to advanced metastatic carcinoid tumour. No patient required re-operation for bioprosthetic degeneration. Dreyfus and colleagues concluded that valve surgery 
for carcinoid heart disease is of higher risk compared with most other forms of valvular surgery. In patients who survived the operation significant improvement in functional class occurred. Most long term complications were related to the tumour itself rather than cardiac complications.

\section{Own experience}

In table 1, we summarised our experience with all types of tumours treated in the time period between 1996 and 2010. We have operated on 95 patients (mean age 58 years, ranging from 44 to 82 years) with a benign cardiac myxoma. Distribution male: female was 1:1.4. The 30 -day mortality rate was $1 / 95$ (1.05\%); one patient did not recover from a preoperative stroke and died from neurologic complications at postoperative day 10. The estimated survival (Kaplan-Meier) at 10 years was $86 \%$. There were no recurrence so far.

In the same time period, we operated on 12 adult patients and seven children presenting with renal cell carcinoma (resp. Wilms tumour) extending either into the inferior vena cava $(n=4)$ or more cranially into the right atrium $(\mathrm{n}=12)$ and in some instances through the tricuspid valve into the right ventricle $(n=3)$. Successful total removal was performed through midline laparotomy and median sternotomy or through thoracophrenico-laparatomy with the aid of normothermic cardiopulmonary bypass. There was no perioperative mortality in these cases. Recurrence occurred within a mean interval of 11 months in three patients.

The experience with malignant and/or metastatic tumour has been much more disappointing. Not included in this short summary are the pericardial drainage and/or the creation of pericardial window (into the pleura or the abdominal cavity) to treat recurrent malignant pericardial effusion.

\section{Conclusion}

Primary cardiac tumours are rare, with an autopsy incidence ranging from $0.001 \%$ to $0.03 \%$ according to different series. $75 \%$ of these tumours are benign and nearly $50 \%$ of the benign tumours are left or right atrial myxomas. Primary cardiac tumours present with one or more of the symptoms of the classic triad of cardiac symptoms and signs resulting from intracardiac obstruction, signs of systemic embolisation, and

\section{Table 1}

Experience with tumour surgery of the heart (Berne, 1996-2010).

\begin{tabular}{|c|c|c|c|}
\hline \multicolumn{2}{|l|}{ Benign cardiac tumours } & \multicolumn{2}{|l|}{$\mathbf{n}$} \\
\hline \multicolumn{2}{|l|}{ Myxoma } & \multicolumn{2}{|l|}{95} \\
\hline \multicolumn{2}{|l|}{ Papillary fibroelastoma } & \multicolumn{2}{|l|}{14} \\
\hline \multicolumn{2}{|l|}{ Fibroma (children) } & \multicolumn{2}{|l|}{4} \\
\hline \multicolumn{2}{|l|}{ Rhabdomyoma } & \multicolumn{2}{|l|}{1} \\
\hline \multicolumn{2}{|l|}{ Malignant tumours } & $\mathbf{n}$ & Deaths within $1 \mathrm{yr}$ \\
\hline \multirow{3}{*}{$\begin{array}{l}\text { Primary malignant cardiac } \\
\text { tumours }\end{array}$} & Sarcoma (not otherwise specified) & 2 & 1 \\
\hline & Angiosarcoma (SVC, IVC, PA) & 6 & 1 \\
\hline & Leiomyosarcoma & 3 & 2 \\
\hline \multirow[t]{3}{*}{ Infra-diaphragmatic tumours } & Wilms tumour & 7 & 1 \\
\hline & Renal cell carcinoma & 12 & - \\
\hline & Endometrial stromal cell sarcoma & 1 & - \\
\hline \multirow[t]{10}{*}{ Metastatic heart tumour } & Metastatic lung carcinoma: debulking RV & 1 & 1 \\
\hline & Metastatic thyroid carcinoma: debulking RA, RV & 1 & 1 \\
\hline & Non Hodgkin Lymphoma: debulking RV, Pericardium & 1 & 1 \\
\hline & Synovialom RV: resection + tricuspid valve replacement & 1 & \\
\hline & Plasmocytoma RV/RA: partial resection & 1 & 1 \\
\hline & Chorio-Carcinoma: resection pulmonary veins, LA & 1 & - \\
\hline & Melanoma RV: palliative resection (debulking) & 1 & 1 \\
\hline & Hamartoma LA: curative resection + MVR & 1 & - \\
\hline & Haemangiosarcoma RV/RA: palliative resection & & - \\
\hline & Lymphangiosarcoma LV: palliative resection & 1 & 1 \\
\hline \multicolumn{2}{|c|}{ Carcinoid heart disease (TVR + PVR) } & 9 & 1 \\
\hline
\end{tabular}


systemic or constitutional symptoms. The majority of cardiac tumours are diagnosed using transthoracic and transoesophageal echocardiography, MRI, and CT scan. Whereas surgery is almost always indicated in patients with benign tumours, systemic chemotherapy is indicated in those who have widespread or unresectable malignant disease, and chemotherapy and radiotherapy are usually combined in treatment of patients with primary cardiac lymphomas. Cardiac sarcomas represent the most frequent histology of primary malignant cardiac tumours, with angiosarcomas making up $33 \%$ of the cases.

The prognosis after surgery is usually excellent in the case of benign tumours (with a perioperative mortality below $1.5 \%$ ) and with a minimal number or absence of recurrence. Unfortunately the prognosis is still limited in localised malignant diseases. Patients with sarcomas live for a mean of three months to one year, and those with lymphomas may reach a life expectancy up to five years if treated. Metastases to the heart are far more common than primary cardiac tumours but they do not usually present to the cardiac surgeons because of the overall dismal prognosis.

\section{References}

1 Guiraudon C. Cardiac tumours. In: Cardiology 2nd edition by Crawford M, DiMarco JP and Paulus WJ. Mosby Edinburgh, London, NewYork, 2004, pp. 1507-14.

2 Bruce CJ. Cardiac tumours: diagnosis and management. Heart. 2011; 97:151-60.

3 Butany J, Nair V, Naseemuddin A, Nair GM, Catton C, Yau T. Cardiac tumours: diagnosis and management. Lancet Oncol. 2005;6:219-28.

4 Salcedo EE, Cohen GI, White RD, Davison MB. Cardiac tumours: diagnosis and management. Curr Probl Cardiol 1992;2:75-138.

5 Ekmektzoglou KA, Samelis GF, Xanthos T. Heart and tumours: location, metastases, clinical manifestations, diagnostic approaches and therapeutic considerations. J Cardiovasc Med. 2008;9:769-77.

6 Reeder GS, Khandheria BK, Seward JB, Tajik AJ. Transesophageal echocardiography and cardiac masses. Mayo Clin Proc. 1991;66: 1101-9.

7 Shah DJ. Evaluation of cardiac masses: the role of cardiovascular magnetic resonance. Methodist DeBakey Cardiovasc J. 2010;6:4-11.

8 DeVille JB, Corley D, Jin BS, de Castro CM, Hall RJ, Wilansky S. Assessment of intracardiac masses by transoesophageal echocardiography. Tex Heart Inst J. 1995;22:134-7.

9 Tolstrup K, Shiota T, Gurudevan S, Luthringer D, Luo H, Siegel RJ. Left atrial myxomas: correlation of two-dimensional and live three-dimensional transesophageal echocardiography with the clinical and pathological findings. J Am Soc Echocardiogr. 2011, Feb 28 [Epub ahead of print].

10 Fussen S, DeBoeck BW, Zellweger MJ, Bremerich J, Goetschalkx K, Zuber M, et al. Cardiovascular magnetic resonance imaging for diagnosis and clinical management of suspected cardiac masses and tumours. Eur Heart J. 2011;32:1151-60.

11 Hoey ET, Mankad K, Puppala S, Gopalan D, Sivananthan MU. MRI and CT appearances of cardiac tumours in adults. Clin Radiol. 2009;64: 1214-30.

12 Jain D, Maleszewski J, Halushka MK. Benign cardiac tumours and tumorlike conditions. Ann Diagn Path. 2010;14:215-30.

13 Miller DV, Edwards WD. Cardiovascular tumorlike conditions. Semin Diagn Pathol. 2008;25:54-64.

14 Oliveira RG, Branco L, Dias L, Timotea AT, Patricio L, Agapito A, et al. Mitral valve myxomas: an unusual entity. Eur J Echocardiogr. 2008;9: $181-3$.
15 Erdös G, Reineke D, Basciani R, Carrel T, Eberle B. Left atrial myxoma attached to the anterior mitral leaflet with symptoms suggestive of infective endocarditis. Eur J Echocardiography. 2010;11:E8.

16 Tönz M, Laske A, Carrel T, da Silva A, Real F, Turina M. Convulsions, hemiplegia, and central retinal occlusion due to a left atrial myxoma in a child. Eur J Pediatr. 1992;151:652-4.

17 Schaff HV, Mullany CJ. Surgery for cardiac myomas. Semin Thorac Cardiovasc Surg. 2000;12:77-88.

18 Bernet F, Stulz P, Carrel T. Long-term remission after combined resection, chemotherapy and irradiation of a metastatic left atrial myxoma. Ann Thorac Surg. 1998;66:1791-2.

19 Reynen K. Cardiac myxomas. New Engl J Med. 1995;333:1610-7.

20 Gegouskov V, Kadner A, Englberger L, et al. Papillary Fibroelastoma of the Heart. Heart Surg Forum. 2008;11:E333-339.

21 Sakaguchi H, Sekii H. Surgical Resection of Cardiac Papillary Fibroelastoma in the Left Ventricular Outflow Tract. Ann Thorac Cardiovasc Surg. 2008;14:393-5.

22 Hort W, Horskotte D. Fibroelastoma and Lambl's excrescences: localization, morphology and pathogenesis, differential diagnosis and infection. J Heart Valve Dis. 2006;15:591-3.

23 Erdös G, Stalder M, Basciani R, Gugger M, Carrel T, Eberle B. An Uncommon Cause of Coronary Artery Ostial Obstruction: Papillary Fibroelastoma Echocardiography. 2010;27:337-40.

24 Yerebakan C, Liebold A, Steinhoff G, Skrabal CA. Papillary fibroelastoma of the aortic wall with partial occlusion of the right coronary ostium. Ann Thorac Surg. 2009;87:1953-4.

25 Uzun O, Wilson DG, Vujanic S, Parson JM, De Giovanni JV. Cardiac tumours in children. Orphanet J Rare Dis. 2007;2:11-5.

26 Günther T, Schreiber C, Noebauer C, Eiken A, Lange R. Treatment strategies for paediatric patients with primary cardiac and pericardial tumours: a 30-year review. Pediatr Cardiol. 2008;29:1071-6.

27 Delgueldre SC, Chockalingam P, Mivelaz Y, DiBernardo S, Pfammatter JP, Barrea C, et al. Considerations form prenatal counselling of patients with cardiac rhabdomyomas based on their cardiac and neurologic outcomes. Cardiol in the Young. 2010;20:18-24.

28 Vidaillet HJ. Cardiac tumours associated with hereditary syndromes. Am J Cardiol. 1988;61:1355-9.

29 Centofanti P, di Rosa E, Deorsola L, Dato GM, Patanè F, La Torre M. Primary cardiac tumours: early and late results of surgical treatment in 91 patients. Ann Thorac Surg. 1999;68:1236-41.

30 Ceitham EL, Midgley FM, Pery LW, Dullum MK. Intramural ventricular fibroma in infancy: survival after partial excision in two patients. Ann Thorac Surg. 1990,50:471.

31 Fuidl M, Kadner A, Loup O, Carrel T. Kardiales Fibrom: Ursache einer unklaren Gedeihstörung bei einem Säugling. Schweiz Med Forum. 2009;14:286-7.

32 Cina SJ, Smialek JE, Burke AP, Virmani R, Hutchins GM. Primary cardiac tumours causing sudden death: a review of the literature. Am J Forensic Med Pathol. 1996;17:271-81.

33 Burke AP, Johns JP, Virmani R. Hemangiomas of the heart: a clinicopathological study of ten cases. Am J Cardiovasc Pathol. 1990;3:28390.

34 Kipfer B, Englberger L, Stauffer E, Carrel T. Rare presentation of cardiac haemangioma. Ann Thorac Surg. 2000;70:977-9.

35 Xanthos T, Giannakopoulos N, Papadimitriou L. Lipomatous hypertrophy of the interatrial septum. A pathological and clinical approach. Int J Cardiol. 2007;121:4-8.

36 Reynolds C, Tazelaar HD, Edwards WD. Calcified amorphous tumour of the heart. Hum Pathol. 1997;28:601-6.

37 Forman MB, Virmani R, Robertson RM, Stone WJ. Mitral anulus calcification in chronic heart failure. Chest. 1984;85:367-71.

38 Lewin M, Nazarian S, Marine JE. Fatal outcome of a calcified amorphous tumour of the heart. Cardiovasc Pathol. 2006;15:299-302.

39 Lee JH, Kang SK, Lee CW, Song JK, Park JS, Choo SJ. Giant left atrial ball thrombus in a patient with chronic non valvular atrial fibrillation. Ann Thorac Surg. 2008;85:313-5.

40 Aguilar JA, Summerson C. Intracardiac thrombus in antiphospholipoid antibody syndrome. J Am Soc Echocardiogr. 2000;13:873-5.

41 Chartier L, Bera J, Delomez M, Asseman P, Beregi JP, Bauchard JJ, et al. Free-floating thrombi in the right heart: diagnosis, management, and prognosis-indexes in 38 consecutive patients. Circulation. 1999;99: 2779-83.

42 Neragi-Miandoab S, Kim J, Vlahakes GJ. Malignant tumours of the heart: a review of tumour type, diagnosis and therapy. Clin Oncol. ( $R$ Coll Radiol) 2007;19:748-56. 
43 Luk A, Nwachukwu H, Lim KD, Cusimano RJ, Butany J. Cardiac angiosarcoma: a case report and review of the literature. Cardiovasc Pathol. 2010;19:e69-74.

44 Vujin B, Benc D, Srdic S, Bikicki M, Vuckovic D, Dodic S. Rhabdomyosarcoma of the heart. Herz. 2006;31:798-800

45 Meng Q, Lai H, Lima J, Tong W, Qian Y, Lai S. Echocardiographic and pathologic characteristics of primary cardiac tumours: a study of 149 cases. Int J Cardiol. 2002;84:69-75.

46 Hugo C, Lederlin M, Bégueret H, Guisset O, Corneloup O, Laurent F. Primary pulmonary angiosarcoma: CT-pathology correlation. J Radiol. 2011;92:46-9.

47 Tueller C, Fischer Biner R, Minder S, Gugger M, Stoupis C, et al. FDGPET in diagnostic work-up of pulmonary artery sarcoma. Eur Respir J. 2010;35:444-6.

48 Llombart-Cussac A, Pivot X, Contesso G, Rhor-Alvarado A, Delord JP, Spielmann M, et al. Adjuvant chemotherapy for primary cardiac sarcomas: the IGR experience. Br J Cancer. 1998;78:1624-8.

49 Grandmougin D, Fayad G, Decoene C, Pol A, Warembourg H. Total orthotopic heart transplantation for primary cardiac rhabdomyosarcoma: factors influencing long-term survival. Ann Thorac Surg. 2001;71:143841.

50 Crespo MG. Heart transplantation for cardiac angiosarcoma: should the indication be questioned? J Heart Lung Transplant. 1993;12:52730.

51 Aravot DJ, Banner NR, Madden B. Primary cardiac tumours. Is there a place for heart transplantation? Eur J Cardio-thorac Surg. 1989;3:5214.

52 Carrel T, Jenni R, Schmid ER, Vorburger C, Largiader F, Turina M. Successful resection of y hypernephroma extending into the right ventricle: utilization of extracorporeal circulation in general surgery. Schweiz Med Wschr. 1991;121:1460-4.

53 Chatterjee T, Müller M, Carrel T, Kaufmann U, Meier B. Renal cell carcinoma with tumour thrombus extending through the inferior vena cava into the right cardiac cavities. Circulation. 1997;96:2729-30.

54 Nesbitt JC, Soltero ER, Dinney CP, Walsh GL, Schrump DS, Swanson DA, et al. Surgical management of renal cell carcinoma with inferior vena cava tumour thrombus. Ann Thorac Surg. 1997;63:1592-600.
55 Renzulli P, Weimann R, Barras JP, Carrel T, Candinas D. Low-grade endometrial stromal sarcoma with inferior vena cava tumour thrombus and intracardiac extension: Radical resection may improve recurrence free survival. Surg Oncol. 2009;18:57-64.

56 Carrel T, Linka A, Turina M. Tricuspid valve obstruction caused by plasmocytoma metastasis. Ann Thorac Surg. 1992;54:352-4.

57 Bohlman M, Eckstein F, Allemann Y, Carrel T. Successful resection of a chorio-carcinoma metastasis from the left atrium with obstruction of the pulmonary veins. Gynecol Oncol. 2002;84:157-60.

58 Bohlmann M, Eckstein F, Carrel T. Amelanotic cardiac melanoma: dismal prognosis despite extensive intracardiac debulking. Br J Dermatol. 2002;146:912-5.

59 Bussani R, De-Giorgio F, Abbate A, Silvestri F. Cardiac metastases. J Clin Pathol. 2007;60:27-34.

60 Catton C. The management of malignant cardiac tumours: clinical considerations. Semin Diagn Pathol. 2008;25:69-75.

61 Bernheim AM, Connolly HM, Hobday TJ, Abel MD, Pellikka PA. Carcinoid heart disease. Prog Cardiovasc Dis. 2007;49:439-51.

62 Castillo JG, Filsoufi F, Adams DH, Raikhelkar J, Zaku B, Fischer GW. Management of patients undergoing multivalvular surgery for carcinoid heart disease: the role of the anesthesiologist. $\mathrm{Br}$ J Anaesth. 2008;101:618-26.

63 Raja SG, Bhattacharyya S, Davar J, Dreyfus GD. Surgery for carcinoid heart disease: current outcomes. Concerns and controversies. Future Cardiol. 2010;6(5):647-55.

64 Arghami A, Connolly HM, Abel MD, Schaff HV. Quadruple valve replacement in patients with carcinoid heart syndrome. J Thorac Cardiovasc Surg. 2010;140:1432-4.

65 Bhattacharyya S, Raja SG, Toumpanakis C, Caplin ME, Dreyfus GD, Davar J. Outcome, risks and complications of cardiac surgery for carcinoid heart disease. Eur J Cardio-thorac Surg. 2010 Dec 16 [Epub ahead of print]. 